\title{
MULHERES, RAÇA E CLASSE
}

Autor: Ângela Davis.

São Paulo: Boitempo Editorial, 2016.

\section{Isabel Dias \\ mdias@letras.up.pt \\ Universidade do Porto - Portugal}

No Prefácio à edição brasileira de Mulheres, Raça e Classe, Djamila Ribeiro, a partir de um breve retrato biográfico de Ângela Davis, abre-nos a janela para os temas tratados nesta obra: a escravidão e seus efeitos, a impossibilidade de se pensar uma sociedade sem se ter em conta a questão racial e, sobretudo, o quanto é necessário "considerar a interseção de raça, classe e género para possibilitar um novo modelo de sociedade" (2016: 12). Com efeito, na obra, Davis desafianos a analisar como tais opressões estruturam a sociedade e perpetuam formas de controlo social afastando-se, desta forma, da esquerda ortodoxa por dar primazia à classe social sobre outras formas de opressão.

Tendo por referência o conceito de interseccionalidade, Davis começa por analisar no capítulo 1 o "Legado da escravidão: parâmetros para uma nova condição da mulher". Evocando o debate alimentado por vários historiadores e académicos sobre o "sentido da instituição peculiar”, eufemismo usado nos Estados Unidos para designar a escravidão, a autora constata que a situação das mulheres escravas permanece incompreendida, mesmo durante a década de 1970, altura em que proliferaram as publicações sobre esta problemática, mas em que era evidente a ausência de "um livro especificamente dedicado à questão das mulheres escravas" (2016: 16). Neste sentido, afirma que "se alguém conseguir acabar, do ponto de vista histórico, com os malentendidos sobre as experiências das mulheres negras escravizadas [...] prestará um serviço inestimável", na medida em que as lições que um estudo desses "pode reunir sobre a era escravista trarão esclarecimentos sobre a luta atual das mulheres negras e de todas as mulheres em busca de emancipação" (2016: 17). A partir daqui propõe algumas hipóteses capazes de orientar um reexame da história destas mulheres. Refere então que a centralidade que o trabalho ocupa hoje na vida das mulheres negras reproduz um padrão original estabelecido no período da escravatura. Nesta altura, as mulheres, tal como os homens negros, eram vistas como unidades de trabalho lucrativas, sendo que como escravas todos os outros aspetos da sua existência estavam ofuscados pelo trabalho compulsório (2016: 17). Portanto, para os proprietários de escravos as mulheres negras eram desprovidas de género, sendo vistas, acima de tudo, como "trabalhadoras agrícolas", principalmente as escravas do Sul dos Estados Unidos.

No domínio do trabalho "a força e a produtividade sob a ameaça do açoite eram mais relevantes do que as questões relativas ao sexo. Nesse sentido, a opressão das mulheres era 
idêntica à dos homens" (2016: 19). Todavia, elas eram vítimas de abuso sexual e de outras formas de violência que só lhes eram infligidas a elas pelo facto de serem mulheres. Mais tarde com a abolição do tráfico internacional e nas décadas que precederam a Guerra Civil dos Estados Unidos (1861-1865), as escravas passaram a valer, de igual modo, pela sua capacidade reprodutiva. No entanto, o que aqui estava em causa não era o seu significado como mães, mas principalmente "como instrumentos que garantiam a ampliação da força de trabalho escrava". Por essa razão, as suas crianças eram transacionáveis tal como qualquer outro animal (2016: 19-20).

Ao mesmo tempo, o sistema esclavagista desencorajava a supremacia masculina dos homens negros, não podendo estes aspirar à condição de chefes de família e menos ainda à de provedores. “Afinal, homens, mulheres e crianças eram igualmente "provedores" para a classe proprietária de mão de obra escrava" (2016: 20), a qual impunha a toda a família a sua autoridade absoluta. Rapidamente, as mulheres tornaram-se mais lucrativas do que os próprios homens escravos e livres, tanto mais que o seu custo de exploração era menor (2016: 23). Mesmo quando a ideologia da feminilidade, que se propagou com a expansão da industrialização, associou as mulheres brancas à economia doméstica, designadamente ao papel de mãe e donas de casa, as mulheres negras permaneceram excluídas deste vocabulário, continuando afetas a uma estrutura produtiva e reprodutiva imposta pelos seus proprietários.

Davis analisa igualmente a estrutura biológica matrilocal da família negra e mostra que nos registos de nascimento de crianças de mulheres escravas só constava o nome da mãe, o que era reforçado pelo princípio do partus sequitur ventrem (2016: 25). Para alguns autores, esta estrutura familiar é resultado do sistema esclavagista, que permitia apenas ao povo negro a organização matrifocal, a qual enfatizava a primazia da relação entre a mãe e a criança assim como a existência de laços frágeis com o homem (2016: 26). A verdade é que apesar de muitas destas famílias serem separadas devido à venda indiscriminada de maridos, mulheres e crianças, "os laços afetivos, as normas culturais que governavam as relações familiares e o desejo preponderante de permanecerem juntos sobreviveram ao golpe devastador da escravidão” (2016: 27).

Mas, ao contrário da mulher branca, as mulheres negras não eram socialmente desvalorizadas pelo trabalho doméstico. Tal como os seus companheiros, elas eram trabalhadoras e não estavam confinadas às funções domésticas. Por isso, segundo Davis, a "vida doméstica tinha uma imensa importância na vida social de escravas e escravos, já que lhes propiciava o único espaço em que podiam vivenciar verdadeiramente suas experiências como seres humanos" (2016: 29). Ao mesmo tempo, os homens escravos desempenhavam tarefas domésticas importantes e não eram vistos como meros ajudantes das mulheres. "As tarefas dos homens não eram nem superiores nem inferiores ao trabalho realizado pelas mulheres [...]. A questão que se destaca na vida doméstica nas sanzalas é a igualdade sexual" (2016: 30). Todavia, a aspiração à igualdade também se estendia ao combate da instituição esclavagista e, por isso, "resistiam ao assédio sexual dos homens brancos, defendiam a sua família e participavam de paralisações e rebeliões" (2016: 31). "As mulheres resistiam e desafiavam a escravidão o tempo todo". E esta resistência ia além da revolta, fuga ou sabotagens. Incluía aprender a ler e a escrever de forma clandestina e a transmitir esse conhecimento, enquanto 
arma poderosa, aos demais (2016: 35). Em suma, a autora mostra neste capítulo que as mulheres negras eram iguais aos homens negros na opressão que sofriam, mas também na resistência ao sistema esclavagista dominante. Paradoxalmente, foi a partir de um sistema que não fazia distinção de sexo, que foram criadas as bases da resistência à exploração humana e da luta pela igualdade entre as mulheres negras (2016: 36). Esta aspiração resistiu, inclusive, às mais cruéis formas de dominação, nomeadamente ao estupro usado pelos proprietários brancos como "uma arma de repressão, cujo objetivo era aniquilar o desejo das escravas de resistir e, nesse processo, desmoralizar os seus companheiros" (2016: 36). A origem da força destas mulheres está nas suas experiências concretas como escravas. Segundo a autora, foi um legado de tenacidade, resistência e insistência na igualdade sexual que estas mulheres escravas transmitiram às suas descendentes.

No segundo capítulo, Davis analisa "O movimento antiescravista e a origem dos Direitos das Mulheres", afirmando que "a causa das pessoas escravas tem sido particularmente uma causa das mulheres" (2016: 43). Partindo desta afirmação, a autora recorda que as mulheres brancas foram necessárias ao movimento abolicionista, sobretudo numa época em que a ideologia da feminilidade, isto é, da mulher e mãe perfeitas, tinha um grande acolhimento na imprensa e na nova literatura em geral. Os escravos, tal como as crianças, eram representados como pessoas indefesas e, por vezes, insolentes (2016: 44). Esta ideologia encontrava-se plasmada na obra de Stowe, A cabana do Pai Tomás, considerada, pela autora, como um veículo de reprodução das ideias racistas subjacentes à escravidão e das noções sexistas que expulsavam as mulheres da arena política onde se fazia o combate à escravatura (2016: 44). Com a industrialização da economia norte americana, o prestígio baseado no carácter produtivo e essencial do trabalho doméstico feminino entrou em declínio, de tal forma que a autora considera que uma das consequências ideológicas mais negativas do capitalismo industrial para as mulheres foi tê-las confinado ao lar, não por força do reconhecimento das suas competências, historicamente demonstradas neste domínio, mas pela afirmação da sua inferioridade de género não lhes restando, por isso, outra alternativa (2016: 45). A década de 1830 emerge com muita turbulência: afirma-se a resistência da população negra; nasce o movimento abolicionista organizado; fazem-se greves e paralisações nas fábricas têxteis do Nordeste do país; as mulheres brancas começam a lutar pelo direito à educação, por uma carreira fora de casa, mas principalmente comparam o casamento à escravidão estabelecendo-se assim, pelo menos entre as mulheres brancas da classe média, uma grande afinidade com a causa das mulheres e homens negros (2016: 47). Através de alguns exemplos de ação cívica, como é o caso de Prudence Crandall que desafiou o código de conduta de uma mulher branca ao abrir a primeira escola exclusiva para a comunidade negra, Davis afirma que desde 1833 irrompera uma nova era de violentas lutas sociais e que doravante seriam vastas as "possibilidades de libertação caso as mulheres brancas, em massa, dessem as mãos a suas irmãs negras" (2016: 48). Refere ainda que ao trabalharem no movimento abolicionista, "as mulheres brancas tomaram conhecimento da natureza da opressão humana - e, nesse processo, também aprenderam importantes lições sobre a sua própria sujeição" (2016: 51).

No terceiro capítulo intitulado "Classe e raça no início da campanha pelos Direitos das mulheres", Davis refere que a conversa que Lucretia Mott e Elizabeth Cady Stanton tiveram no 
dia de abertura da Convenção Antiescravista Mundial de 1840, "conta a verdadeira história do nascimento do movimento organizado de mulheres nos Estados Unidos" (2016: 57), acrescentando que este movimento "foi principalmente inspirado - ou até mesmo provocado - pela intolerável supremacia masculina no interior da campanha antiescravagista" (2016: 57). Embora de forma embrionária, a defesa dos direitos das mulheres, apoiada também pela população negra que lutava pela própria liberdade, tornou-se numa questão pública nos Estados Unidos (2016: 63). O ataque voltava-se para a instituição matrimonial e os seus efeitos prejudiciais na vida das mulheres (e.g. ausência de direito à propriedade; dependência moral e económica dos maridos, exigência de submissão absoluta ao homem e à sua autoridade). Esta condição foi revelada na Declaração de Seneca Falls, na qual se afirmava que a "inferioridade das mulheres no interior do casamento" também as sujeitava a outras desigualdades nas instituições de ensino e na carreira (2016: 63). Assim, neste capítulo, Davis dá-nos conta de alguns episódios históricos que marcaram a luta das mulheres, brancas e negras, pela conquista de direitos fundamentais e mostra-nos como elas estavam efetivamente unidas nesse processo, pois, o que estava em causa não era apenas a opressão racista, mas também a dominação sexista (2016: 70).

No quarto capítulo, a autora aborda o "Racismo no movimento sufragista feminino" e mostra como a proposta de unir a causa das mulheres com a causa negra, isto é, a pretensão de situar ambas as causas numa "plataforma por direitos humanos" (2016: 80) foi barrada pelo "profundo vínculo ideológico entre racismo, viés de classe e supremacia masculina" (2016: 81). Mostra ainda que a suposição de que a emancipação tornava os ex-escravos iguais às mulheres brancas, precisando ambos os grupos de conquistar o voto para completar sua igualdade social, "ignorava a total precariedade da recém-conquistada liberdade da população negra após a Guerra Civil (2016: 85). Como diz a autora, apesar da abolição da escravidão, a população negra ainda estava refém de uma pobreza extrema e era perseguida pelos gangues racistas com uma violência que, muitas vezes, superava a da era esclavagista. Esta condição levou à defesa do direito ao voto pelos homens negros como forma de obterem poder político e de garantir a sua sobrevivência, antes mesmo das mulheres brancas, o que conduziu a um intenso debate com as defensoras do sufrágio feminino (2016: 88).

No quinto capitulo Davis analisa o "significado de emancipação para as mulheres negras" referindo que após "um quarto de século de liberdade" apenas poucas mulheres conseguiram escapar ao trabalho no campo, na cozinha ou na lavandaria e as que encontravam emprego na indústria estavam confinadas à realização dos trabalhos mais sujos e pior remunerados (2016: 95). Assim, as condições de trabalho para as mulheres negras não eram muito distintas da época anterior à Guerra Civil, pois apesar de existirem contratos com a entidade patronal "uma grande quantidade de pessoas negras viu-se num estado indefinido de servidão por dívida" (2016: 96). O mesmo sucedia com a mão de obra carcerária, que era usada com regularidade e sem qualquer diferenciação entre o trabalho feminino e masculino. Portanto, a emancipação não erradicou a violência sobre as mulheres negras, que passou a ser exercida principalmente pelo sistema judiciário, que não as protegia dos ataques sexuais por parte dos homens brancos, pelo contrário, se elas resistissem "eram jogadas na prisão para serem ainda mais vitimizadas por um sistema 
que era um retorno a outra forma de escravidão" (2016: 98). Assim, Davis mostra que a situação das mulheres negras "não mostrou sinais de mudança até ao início da Segunda Guerra Mundial" (2016: 105) e mesmo quando esta as lançou massivamente para a indústria em substituição dos homens, "os sinais de liberdade eram sombras tão vagas e distantes que era preciso forçar os olhos para vislumbrá-las" (2016: 106). No sexto capítulo, a autora aborda a questão da "educação e libertação" e salienta que para além da posse de terras e do direito ao voto a população negra reivindicava, de igual modo, o direito à educação. Mas foi graças à união das mulheres negras e brancas que a luta contra o analfabetismo no Sul atingiu o seu auge.

No capítulo 7, Davis faz a análise da luta pelo sufrágio feminino e a sua associação à questão do racismo, referindo que este nem sempre foi uma preocupação pública do movimento sufragista (2016: 118). Mostra também que as primeiras experiências de organização associativa entre as mulheres negras datam do período pré-Guerra Civil. Estas associações estavam muito focadas na causa antiescravagista, nas necessidades de sobrevivência do povo negro, na "onda de linchamentos" e no "abuso sexual indiscriminado" que vitimava inúmeras mulheres (capítulo 8). Além disso, ao contrário das suas congéneres brancas, as líderes das associações de mulheres negras diferenciavamse das primeiras porque tinham consciência da necessidade de combater o racismo. No capítulo 9, Davis retoma a história do movimento sufragista a par da crescente consciencialização dos direitos das mulheres trabalhadoras, em particular entre a classe operária que emergia, cada vez mais, como uma força económica e social em expansão. Na indústria de confeções, as mulheres, principalmente negras, começaram a organizar-se e o "espírito da sindicalização" espalhou-se por praticamente todas as grandes cidades onde aquela indústria prosperava (2016: 143). Mas as mulheres negras continuavam praticamente invisíveis no interior da longa campanha pelo sufrágio feminino" (2016: 146). Na verdade, a "massa das trabalhadoras estava mais preocupada com seus problemas imediatos - salários, jornadas, condições de trabalho - para lutar por uma causa que parecia imensamente abstrata" (2016: 146). Só no início do século XX (1909-1910) é que as mulheres (trabalhadoras) se "uniram em massa para levantar a bandeira do sufrágio", passando este a ser entendido como uma arma poderosa na luta de classes, ou seja, as trabalhadoras precisavam do direito ao voto para garantirem "salários mais altos e melhores condições de trabalho" (2016: 148). Todavia, a criação de um movimento multirracial pelos direitos políticos das mulheres sofreu muitas investidas das líderes brancas do movimento sufragista, pois as mulheres negras eram facilmente dispensáveis quando se tratava de conquistar o "apoio das brancas do Sul" (2016: 153). E mesmo quando as mulheres negras conquistaram o direito ao voto, as violências de que eram alvo quando tentavam exercê-lo passaram a combinar "restrições de sexo, raça e classe" (2016: 149).

No décimo capítulo Davis mostra como o Partido Socialista se associou à luta pela igualdade das mulheres, assim como à defesa do sufrágio feminino. Todavia, este Partido não fora, inicialmente, sensível à causa específica da opressão do povo negro, nem das mulheres negras, pois considerava que estas ainda eram em número insignificante na indústria e apenas o "proletariado era importante para o seu movimento" (2016: 157). Segundo a autora, esta postura "negligente dos socialistas" face às mulheres negras foi "um dos legados infelizes que o Partido 
Comunista teve de superar", o qual reconheceu, nas décadas a seguir a 1920, a centralidade do racismo na sociedade dos Estados Unidos (2016: 157). De seguida, a autora dá a conhecer a história de um conjunto de mulheres ativistas que atuaram em causas socialistas e comunistas.

No capítulo seguinte (11. ${ }^{\circ}$ ), Davis retoma o tema do estupro afirmando que este tipo de crime constitui "uma das mais marcantes disfunções da sociedade capitalista atual" e um "dos artifícios mais impiedosos criados pelo racismo", o qual atinge principalmente mulheres negras, mas também homens negros, que são acusados indiscriminadamente de perpetradores, mesmo quando são inocentes (2016: 179). A este propósito, refere que os homens da classe capitalista e da classe média são imunes aos processos judiciais porque cometem as agressões sexuais com a mesma autoridade incontestada que legitima as suas agressões contra o trabalho e a dignidade dos trabalhadores (2016: 201). Por isso, defende que "o racismo deve ser um tema recorrente do movimento antiestupro, que deve defender não apenas as mulheres de minorias étnicas, mas também as muitas vítimas da manipulação racista das acusações de estupro" (2016: 203).

Davis encerra a presente obra com um capítulo $\left(12^{\circ}\right.$.) dedicado à análise do nascimento da campanha pelo controle da natalidade que suscitou, tal como a defesa do sufrágio feminino, fortes reações, sendo considerada como uma afronta pois uma mulher não "tinha o direito de recusarse a satisfazer os anseios sexuais do marido" (2016: 205). Mas se esta campanha pela "maternidade voluntária" continha uma visão progressista da condição da mulher, permitindo-lhe aspirar a "caminhos de autodesenvolvimento fora do casamento e da maternidade" (2016: 210), sobretudo para as mulheres das classes médias e da burguesia, já as mulheres da classe trabalhadora estavam envolvidas "numa luta muito mais fundamental pela sobrevivência económica" (2016: 210). Rapidamente o viés de classe e o racismo se infiltraram no movimento pelo controle de natalidade, passando este a ser entendido como um direito para as mulheres privilegiadas, mas como um dever para as "mulheres pobres, tanto negras quanto imigrantes" (2016: 213). A autora dedica o último capítulo $\left(13 .^{\circ}\right)$, à denúncia da invisibilidade das tarefas domésticas e ao seu não reconhecimento como trabalho, demonstrando a sua natureza opressora. Conclui que um dos objetivos estratégicos da libertação feminina consiste na abolição das tarefas domésticas como responsabilidade privada e individual das mulheres (2016: 244).

Por último, resta-nos acrescentar que este livro constitui uma referência incontornável da literatura feminista e que, tal como refere Ribeiro, ele "traz as inquietações necessárias para que o conformismo não nos derrote" atribuindo às mulheres negras um "papel essencial, por se tratar de um grupo que sendo fundamentalmente o mais atingido pelas consequências de uma sociedade capitalista, foi obrigado a compreender, para além das suas opressões, a opressão de outros grupos" (2016: 13). Quanto à autora, ela é seguramente, "uma mulher à frente do seu tempo" (2016: 11).

\section{BIBLIOGRAFÍA}

- Davis, Ângela (2016): Mulheres, raça e classe. São Paulo: Boitempo Editorial. 